\title{
Mădălina Bălășescu, Mass-media: reprezentări sociale și stereotipuri. Societate, democrație, rol social, Editura Tritonic, București, 2013, 284 p.
}

\author{
Armanda Ramona Stroia* \\ Faculty of Letters, Technical University of Cluj-Napoca, North University Centre, Str. Victoriei 76, 430122 Baia Mare, Romania
}

Within the present context of a society which seems to gravitate around the Palo Alto axiom according to which everything communicates, around a society conquered by communication (B. Miège) and governed by the so-called mediacracy, Mădălina Bălășescu's book, published by Tritonic, at the end of 2013, can be included within Romanian contributions aimed at investigating the vast and heterogeneous field of media communication. Undoubtedly, the importance of the work largely derives from the author's bold choice for a controversial research topic, yet still difficult within the area of Romanian studies. In this respect, the volume seeks to provide an explanatory context for how the media (re) constructs the social imagery, particularly through its symbolic and ideological dimension "from the position of ideological content generator and source of social discourse (values, meanings, codes, cognitive schemes)"(p. 264).

Although the study attempts-through its clearly stated objective-to identify how the Romanian Parliament is mirrored in the central press, the author admits that the option to analyse social representations and stereotypes in the media is in fact a "methodological and theoretical pretext" for an insight into the complex phenomenon of media. With a thematic nucleus organized into five chapters, the paper adopts instruments, operational concepts and explanatory theoretical models from the generous scientific area of sociology and social psychology: structuralism, functionalism, studies of the effects on audience, agenda-setting theory, spiral of silence, constructivism, broadcasting theories, technological approach, hegemonic vision.

Undoubtedly, we must recognize the difficulty of the task-invoked by the author herself from the very beginning - namely the attempt to circumscribe from a theoretical perspective the heterogeneous landscape of media research. Therefore, the first chapter attempts to outline, without any claims of being exhaustive, the vast theoretical background of scientific approaches to media through a simple overview of the most influential theories.

Among the pioneers who have addressed this issue are named the American sociologist Walter Lippman, considered to be the author of the first book on public opinion and Gustave Le Bon, perceived as the father of social psychology and of the classic portrayal of crowds in society. We cannot neglect the consistency with which the author quotes especially from the work of the French sociologist Francis Balle or Mark Balnaves to outline the major sociological models of communication (Harold D. Laswell, Claude Shannon, Warren Weaver, Jacques Ellul, Marshall MacLuhan). Undoubtedly, the author's constant resort to secondary sources-in an effort of theoretical synthesis-is deductible from the undesirable proliferation-even for an ingenuous reader-of apud citations in the footnotes. Hence, her frequent reluctance to critically analyse these paradigms might be related to the above-mentioned tendency.

On the other hand, the author of the present volume is obviously concerned with an organization of the major directions of media studies, as coherent as possible, in terms of two fundamental categories: the normative perspective encompassing essentially prescriptive theories (structuralism, functionalism, studies effects on the audience) and the critical one (hegemonic perspective). In fact, these criteria subsume the two opposing paradigms that have dominated the debate over media for a long time: empirically-oriented theories, respectively the critical paradigm. Generally, we find here an approach defective in terms of critical analysis, in the sense that the author, as she herself admits, simply provides a concise presentation of the most significant theoretical models based on the empirical direc-

\footnotetext{
*Email address: armanda_ramona@yahoo.com.
} 
tion of media research: agenda-setting theory (Maxwell McCombs), spiral of Silence (Elisabeth Noelle Neumann), constructivism, broadcast theory (Rogers Everett curve S), uses and gratifications model, technological approach (Marshall MacLuhan, Harold Innis, Jerry Mander).

In opposition to the empirical orientation, the critical approach (hegemonic vision) emphasizes the idea of social domination and control through media which is associated with society and mass culture, with cultural standardization and propaganda, these phenomena being held responsible for producing stereotypes in thinking and behavior. Emblematic of this is the radical vision of the Frankfurt School's representatives.

Adhering to Denis McQuail's vision, the author highlights the three representative directions within the hegemonic paradigm: the perspective of political economy (Marxism, Neo-Marxism), the critical sociocultural perspective on mass communication (Frankfurt School with Marxist influences) and the ideological-cultural one (School of Birmingham). According to Bălășescu's view, the common denominator of the above mentioned theories is represented by the idea that "mass media is the most important social vector through which the ruling class at a time in a society imposes its vision on others through ideology, values." (p. 48). The adepts of the ideological-cultural model postulate-through Stuart Hall's outstanding contribution-media's role of qualitative and quantitative leader, but also its function of cultural and ideological "colonization". Finally, mass media contributes to the development of a substantial repertoire of "images, meanings, values and practices of groups and social classes" and thus provides "an inventory of modern capitalism's lifestyles and ideologies" (p. 50).

The second chapter outlines the theoretical background necessary for the analysis of media from the perspective of its relationship with society (p. 91), addressing through a synthetic, descriptive approach, without analytical claims, some of the key concepts associated with social organization: systems, social change, transition, political regimes, democracy, liberalism, social role of the media.

The first part of the third chapter provides a concise theoretical framework in order to define "the two almost symbiotic concepts" (p. 95), public space and public opinion, to highlight the central role of the media in the dynamics of this conceptual trinome: "media is the social protagonist in the democratic public space, actively contributing to create the public agenda" (p. 156). The brief insight into the public space theory is organized around the "classical" perspective and the current one. Public space is defined through the established perspective of the German sociologist and philosopher Jürgen Habermas due to his outstanding work Public Sphere and its Structural Transformation which identifies the elements of the public sphere in the context of historical classical patterns: Greek model, the Renaissance one, the modern age typical models-liberalism, socialism, social state (p. 98).

According to the current perspective, the new public space is configured through the dimensions of citizenship, media, technical mediation, the organization, education, and identity. The common denominator of these visions resides, in B. Miège's perception, in shaping the new public space characterized by asymmetry and fragmentation.

In the second part of the chapter the author assigns less space for her attempt to provide a theoretical framework for public opinion, perceived as an ambiguous concept, within the "vast, diverse, sophisticated" theoretical field (p. 125) of the interdisciplinary approaches, combining among others, communication sciences, sociology, psychology, statistics. In this section, the reader's attention is focalized on the theoretical clarification of the concept of public opinion through the established perspective of Elisabeth Noëlle Neumann, that of Habermas and only tangentially through the Romanian research, with limited reference to the contribution of Septimiu Chelcea.

Of course, the author clearly emphasizes the German researcher's contribution to the theoretical crystallization of this concept through the means of a historical insight aimed at retracing the germs of the idea of public opinion in terms of the most significant literary, historical and philosophical sources. Of these, Bălășescu mentions Niccolò Machiavelli's Prince, John Locke's Essay Concerning Human Understanding, Descartes' meditations, but she also points out the contribution of Jean-Jacques Rousseau, Alexis de Tocqueville, Edward Ross, respectively Harwood Childs, the prolific author of "the 50 definitions of public opinion", excellently synthesized by NoëlleNeumann under the umbrella of two interpretations: public opinion - as "rational space in which individual opinions coagulate in the democratic back- 
ground", respectively public opinion - as "authority invested with the role of social cohesion necessary for action and overall decision" (p. 129).

The author not only outlines the representative dimensions of public opinion (political, social, psychosocial, individual, communicative), but she also approaches this concept by inserting it in conceptual equations relevant for the distinctions brought about: public opinion - public sphere, meanings, coding, stereotypes. Having in mind the explanatory context provided by the agenda-setting model, the conclusions of the author are articulated on the major role that media plays in the dynamics of symbolization and of social ideology production, from the position of "social protagonist in democratic public space, actively contributing to the creation of public agenda" (p. 156).

The fourth chapter focuses on an analysis of the media from an institutional perspective and examines various aspects related not only to media production, but also to the often conflicting dynamics between the elements of professional culture (ethics, deontology, fairness, democracy, public interest) and those of the organizational culture, in order to provide the essential coordinates which mark the journalistic system.

In this context it becomes interesting to follow the trajectory of media analysis from a constructivist perspective. According to this theory, mass media is nothing but a social construction of reality, while the so-called objectivity invoked by journalists is actually a utopia, a variable controlled by factors such as economic pressures, political and technological dynamics. This constructivist analysis adopts plausible arguments from the organizational sphere and therefore records "the factors which appear in nodals of media hub" (p. 191): definition of the event, the selection of sources, methods for prioritizing and preparing the "informational menu", techniques of "packaging" the information. On the other hand, in the spirit of positivist paradigm, journalists indulge themselves "in the position of heroes loyal to the world in which they live, claiming that they render raw information and facts" (p. 190).

But this supposed objectivity is articulated from a conceptual point of view around a rich, consistent mythological repertoire, along with other classic professional stereotypes of: "hero, tireless investigator, promoter of total freedom of expression" (p. 191).
The last chapter-smaller in size in comparison to the theoretical sections-proposes a contentanalytic investigation, focused, strategically, on a representative sample which is based on a corpus of 339 texts excerpted from the online editions of the newspapers Adevărul, Evenimentul Zilei, Gândul, România Liberă for a three-month period. The author of the study has chosen to refer to stereotype through the sociological interpretation grid of Walter Lippmann, in whose vision stereotype is perceived as a mechanism for adaptation in society, for encoding reality and life philosophy, developing clear affinities with symbols through its emotional overtones.

An element of clear originality of the present study derives from the subtle identification of a double stereotype within the same content: the social stereotype synonymous, in author's view with "the social image of that content topic" and media stereotype, namely "the shape taken by content in media” (p. 253). The general elements characteristic of social stereotype, detected after the analysis, are centred, in author's perception, around highlighting the following types of stereotype: hegemonic, elite, redundant through the quadrant theory, cultural studies paradigm, respectively the hegemonic model. The framing effect, a key concept excerpted from the theory of agenda-setting plays a vital role in understanding the relationship between society and the media. It involves the process of cutting out fragments of reality and disseminating them in the public space "through repetition and association with cultural symbols families" (p. 41), using special cognitive schemes designed to activate the audience's mental constructions.

Overall, we believe that the study results validate the premise according to which media is "the most important social image and cultural frames creator in society, be it implicit or explicit" (p. 266) and may represent a possible starting point in the analytical investigation of stereotypes in the media.

Beyond some vulnerabilities visible in the effort of theoretical synthesis, the work is, especially in terms of practical investigation, a useful, interesting and highly welcomed contribution in the field of media research, aimed to draw attention of a diverse category of readers, ranging from students and professionals in the vast area of media communication to the wider public as well. 